\title{
A Skeletal Muscle-Derived Secretory Protein, Attractin, Upregulates UCP-2 Expression in Mouse 3T3-L1 Adipocytes
}

\author{
Takeshi Nikawa ${ }^{\dagger}$, Reiko Nakao, Yuki Asanoma, Rumiko Hayashi, Harumi Furochi, \\ Katsuya Hirasaka and Kyoichi Kishi
}

Department of Nutritional Physiology, Institute of Health Biosciences, The University of Tokushima Graduate School, Tokushima 770-8503, Japan.

\begin{abstract}
Skeletal muscle is a major organ involved in the homeostasis of glucose and lipid metabolism. Here, we report that a muscle-derived secretory protein, attractin, highly expressed under unloading conditions, could regulate the expression of uncoupling protein-2 (UCP-2), which is a proton carrier that uncouples electron transport from ATP synthesis, in adipocytes. Attractin has two alternative splicing variants: membrane-bound and secreted forms. Since loss-of-function mutations in membranebound attractin decreases body weight by suppressing appetite in mice, we hypothesize that secretedtype attractin also could regulate energy homeostasis. We first showed that unloading conditions, such as spaceflight and tail-suspension, increased the amount of secreted-type attractin mRNA in rat gastrocnemius muscle. Next, co-culturing of attractin-overexpressing COS7 cells with 3T3-L1 adipocytes or L6 myotubes revealed that secreted-type attractin increased the amounts of UCP-2 mRNA and protein in 3T3-L1 adipocytes, but not in L6 myotubes. Secreted-type attractin failed to upregulate expression of UCP-1 and UCP-3 in 3T3-L1 adipocytes. Two-dimensional polyacrylamide gel electrophoresis also showed that expression of several proteins were up- or down-regulated in 3T3-L1 adipocytes co-cultured with attractin-overexpressing COS7 cells, whereas the profile of protein expression hardly changed in the co-cultured L6 myotubes, indicating that secreted-type attractin preferentially affects adipocytes more than myotubes. Our present study suggests that secreted-type attractin may function as an energy regulating factor in skeletal muscle by upregulating UCP-2 expression level in adipocytes.
\end{abstract}

Key words: Attractin, Adipocytes, Myokine, UCP-2, Unloading conditions.

\section{Introduction}

Skeletal muscles are vulnerable to rapid and marked atrophy under microgravity conditions. Under these conditions, increased protein breakdown is responsible for the muscle wasting, in addition to the decline of muscle protein synthesis (Tischler et al., 1990; Ikemoto et al., 2001). We previously reported that the ubiquitinproteasome proteolytic pathway mainly accounts for the unloading-induced muscle atrophy (Ikemoto et al., 2001; Ogawa et al., 2006). Skeletal muscle is not only locomotorium, but also an organ involved in the homeostasis of glucose and lipid metabolism (Berger et al., 1982; Ryan, 2000; Stein and Wade, 2005). Interestingly, physical inactivity of skeletal muscle leads to insulin resistance and altered energy balance (Biolo et al., 2005; Gianni et al., 2005), in addition to muscle atrophy and reduced exercise capacity. Therefore, we

Article ID: 062002004

Original paper

Received August 22, 2006

Accepted October 9, 2006

To whom correspondence should be addressed: Department of Nutritional Physiology, Institute of Health Bioscience, The University of Tokushima Graduate School, Tokushima 770-8503, Japan.Tel.: +81-(0)88-633-9248; Fax: +81-(0)88-633-7086; E-mail: nikawa@nutr.med. tokushima-u.ac.jp hypothesize that for the homeostasis under unloading conditions, skeletal muscle produces and secretes bioactive factors (myokines) in the same way that fat tissue secretes adipokines, such as leptin and adiponectin (Axelsson et al., 2005).

We previously examined comprehensive gene expression of rat skeletal muscle after spaceflight and found remarkably high expression of a secreted protein, so called attractin (Nikawa et al., 2004). Attractin has two alternative splicing variants: membranebound and secreted forms (Kuramoto et al., 2001). Membrane-bound attractin is also named as mahogany, a type I transmembrane protein, which functions as an accessory receptor for Agouti protein (He et al., 2001). Loss-of-function mutations in the membrane-bound attractin suppresses body weight as well as synthesis of pheomelanin, suggesting that membrane-bound attractin is involved in obesity through the antagonistic action of Agouti protein against melanocortin-1 receptor (He et al., 2001). In contrast, the functions of secreted-type attractin for energy homeostasis are still unknown.

Uncoupling proteins (UCPs) encode proton carriers that uncouple electron transport from ATP synthesis and are implicated in increases in energy expenditure (Gonzalez et al., 2003; Dridi et al., 2004; Wolkow et $a l ., 2006)$. They are known to uncouple respiration from ATP synthesis by short circuiting the inward proton flow, resulting in heat production (Dridi et al., 2004). 
$\mathrm{UCP}-1$ is uniquely present in mitochondria of brown adipocytes. UCP-2 is ubiquitous and highly expressed in the lymphoid system, macrophages, and pancreatic islets. UCP-3 is mainly expressed in skeletal muscles. Unlike $\mathrm{UCP}-1, \mathrm{UCP}-2$ and UCP-3 are involved in adaptation to increased fatty acid oxidation (Rousset et al., 2004; Ricquier, 2005).

In the present study, we examined effects of secretedtype attractin on UCP expression in adipocytes to elucidate its hormonal action on lipid metabolism. Since recombinant attractin produced by $E$. coli was insoluble, we examined effects of secreted-type attractin on adipocytes, by using the co-culturing system of COS7 cells expressing secreted-type attractin with fully differentiated 3T3-L1 adipocytes or L6 myotubes.

\section{Materials and Methods}

\section{Animals}

In the STS-90 mission, male Sprague-Dawley rats ( $\sim 8$ days of age) stayed in space for 16 days in the space shuttle Columbia as described previously (Nikawa et al., 2004). We also subjected male Sprague-Dawley rats (8 days of age) to tail-suspension for 16 days (Nikawa et al., 2004). Isolated gastrocnemius muscles were immediately frozen in chilled isopentane and liquid nitrogen and stored at $-80^{\circ} \mathrm{C}$ until analysis. To examine what factors induced changes in attractin gene expression after unloading, male Wistar rats (12-week-old) were treated with dexamethasone (Wako, Osaka, Japan) or hydrogen peroxide (Wako), as described previously (Fedorak et al., 1995; Lindy and Wilson, 1965; Sato et al., 2006). We determined the doses of dexamethasone and hydrogen peroxide according to these previous studies, because they showed that the administration did not produce any mortality or clinical severe symptoms. Briefly, dexamethasone $(2 \mathrm{mg} / \mathrm{kg} /$ day $)$ was administered orally to rats $(n=5)$ for 2 weeks. Other experimental rats $(n=5)$ were given free access to water containing $100 \mathrm{mM}$ hydrogen peroxide for 2 weeks. The respective control rats ( $\mathrm{n}=6$ per group) were studied in parallel. On the last day, dexamethasone-treated, hydrogen peroxidetreated or the respective control rats were killed after fasting for 16 hours, and the gastrocnemius muscle was immediately isolated.

All animal experiments were performed according to the Guide for the Care and Use of Laboratory Animals (1985) and were approved by the Animal Care Committee of National Aeronautics and Space Administration (NASA), Japan Aerospace Exploration Agency (JAXA) or the Committee for Animal Care in The University of Tokushima School of Medicine.

\section{Co-culturing and transfection}

Mouse 3T3-L1 preadipocytes, rat L6 myoblasts and COS7 cells were purchased from Dainippon Pharmaceutical Co. (Osaka, Japan). They were maintained and proliferated at $37^{\circ} \mathrm{C}$ with $5 \% \mathrm{CO}_{2} / 95 \%$ air in Dulbecco's modified Eagle's medium (DMEM), supplemented with $10 \%$ fetal calf serum, $100 \mathrm{U} / \mathrm{ml}$ penicillin, and $0.1 \mathrm{mg} / \mathrm{ml}$ streptomycin.

In co-culturing, 3T3-L1 preadipocytes were cultured on a semipermeable support membrane in 6-well cellculture inserts (BD Falcon, Franklin Lakes, NJ) at a density of $0.5 \times 10^{5}$ cells/insert (Fig. 1). Only humoral molecules can pass through the membrane. After the cells reached $100 \%$ confluence, they were incubated in adipogenesis induction DMEM, containing 0.25 $\mu \mathrm{M}$ dexamethasone, $0.5 \mathrm{mM}$ isobutyl-methylxanthine and $5 \mu \mathrm{g} / \mathrm{ml}$ insulin, for 2 days (Smith et al., 2003). Then, the cells were further incubated for 9 days in an adipogenesis maintenance DMEM, containing 5 $\mu \mathrm{g} / \mathrm{ml}$ insulin and fully differentiated into adipocytes. Staining with Oil-Red-O solution (in 60\% isopropanol) for 10 min confirmed the full differentiation (data not shown). Whereas, COS 7 cells were plated $\left(0.5 \times 10^{5}\right.$ cells/wells) in 6-well cell-culture dishes (BD Falcon, Franklin Lakes, NJ) and cultured up to about $50 \%$ confluence (Fig. 1). They were transfected with the purified plasmid containing secreted-type attractin (pcDNA3.1D/V5-His-tagged attractin) or $\beta$-galactosidase gene (pcDNA3.1D/V5-His/lacZ) by using FuGene6 (Roche Diagnostics, Mannheim, Germany), according to the method of Hellgren et al., 2000. pcDNA3.1D/ V5-His-tagged attractin was constructed using reverse transcription-polymerase chain reaction (RT-PCR) and cloning techniques as described previously (Onishi et al., 2005). Since the length of rat attractin gene is long (3.8

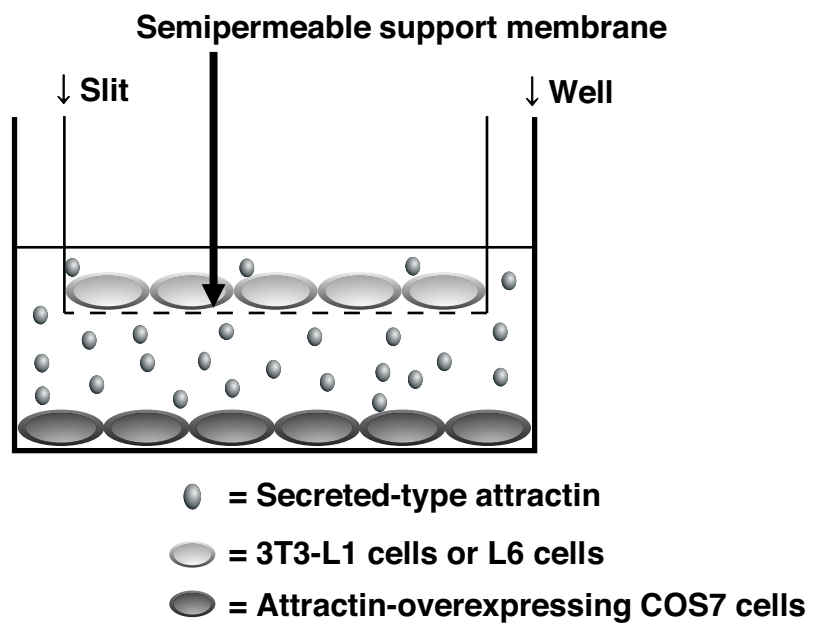

Fig. 1. Co-culturing system.

3T3-L1 preadipocytes or L6 myoblasts cultured on slit were cultured in 6-well cell-culture inserts on a semipermeable support membrane and they were fully differentiated to adipocytes or myotubes, as described in Materials and Methods. COS7 cells cultured on well were transfected with the plasmid containing secreted-type attractin. At 24 hours after transfection, the slits culturing 3T3-L1 adipocytes or L6 myotubes were placed on the well culturing COS7 cells. After $48 \mathrm{hr}$-incubation, COS7 cells and 3T3-L1 adipocytes or L6 myotubes were harvested respectively, and their mRNA or protein was extracted. 
$\mathrm{kbp}$ ), two parts of full gene were individually amplified with two sets of primers (primer sets for 5'-half-gene: 5'TTCCGGATCCATGGTGGCGGCGGCGGCGGC-3' and 5'- GACATCGTGATGGAGCTCAGGTCTGGGGAG-3'; p ri m e r s e t s for 3' - half-gen e : 5' CTCCCCAGACCTGAGCTCCATCACGATGTC-3' and 5'-CCCGAATGAGGGCCCGAAGTAACTCTTACT-3') and subcloned into pBluescript II (Stratagene, Garden Grove, CA). After confirming the sequences, two kinds of cDNA were ligated and inserted into a mammalian expression vector pcDNA3.1D/V5-His (Invitrogen, Carlsbad, CA). At 24 hours after transfection, the slits culturing 3T3-L1 adipocytes were placed on the well culturing COS7 cells, as shown in Fig. 1. In some experiments, we co-cultured the transfected COS7 cells with L6 myotubes fully differentiated by treatment with $2 \%$ horse serum. After 48-hour-incubation, COS7 cells and 3T3-L1 adipocytes were harvested separately, and their mRNA or protein was extracted.

\section{Semi-quantitative RT-PCR}

Total RNA was extracted with an acid guanidinium thiocyanate-phenol-chloroform mixture (Isogen ${ }^{\mathrm{TM}}$; Nippon Gene, Tokyo, Japan), according to the standard protocol. First strand cDNAs were reverse-transcribed at $42^{\circ} \mathrm{C}$ for $60 \mathrm{~min}$ from $1 \mu \mathrm{g}$ of total RNA with oligodT15 primer. PCR reactions were carried out using Taq polymerase (Promega, Madison, WI) and the following primer sets: 5'-CAGGCTTCCAGTACCATTAGG-3' and 5'-GTAAGCATTGTAGGTCCCCGT-3' for mouse UCP-1; 5'-AGGGGAGAGTCAAGGGCTAGT-3' and 5' -ATCCCTTCCTCTCGTGCAATG-3' for mouse UCP-2; 5'-GGACTCTCACCTGTTCACTGACAACT-3' and 5'-CGCAGTACCTGGACTTTCATCAAGG-3' for rat UCP-3; 5'-AGAGTGAATTCTTAACGTCATTCGG-3' and 5'-GATGCGAATTCTGGCTGGCCAGCAA-3' for rat s e c reted-ty pe a t $\mathrm{ractin}$; 5' - CTCCCAGCACAGGAATTCTATGGAC-3' and 5'-CTTCCCCCAATGAATTCAGGAGGTT-3' for mouse membrane-type attractin; 5 , -TCATGACCACAGTCCATGCCATCACT-3' and 5'-GCCTGCTTCACCACCTTCTTGATGT-3' for glyceraldehyde-3-phosphate dehydrogenase (GAPDH). The template was denatured for $5 \mathrm{~min}$ at $94^{\circ} \mathrm{C}$, followed by 25 cycles of the following cycling profile: $30 \mathrm{sec}$ at $94^{\circ} \mathrm{C}, 45 \mathrm{sec}$ at $54^{\circ} \mathrm{C}, 60 \mathrm{sec}$ at $72^{\circ} \mathrm{C}$. The amplification was terminated 10 min later at $72^{\circ} \mathrm{C}$ when PCR products were linearly amplified. The PCR products were separated by electrophoresis in an $8 \%$ polyacrylamide gel and detected with a highly sensitive nucleic acidstaining reagent (TaKaRa, Tokyo, Japan).

SDS-or two dimensional-polyacrylamide gel electrophoresis (2D-PAGE)

For SDS- PAGE, proteins were extracted from COS7, L6 and 3T3-L1 cells with $50 \mathrm{mM}$ Tris- $\mathrm{HCl}$ buffer, $\mathrm{pH}$ 7.5 , containing $150 \mathrm{mM} \mathrm{NaCl}, 1 \%$ Triton $\mathrm{X}-100,1$ tablet of protease inhibitor cocktail (Roche Diagnostics, Basel,
Switzerland), and $10 \mu \mathrm{M}$ epoxomicin per $25 \mathrm{ml}$ of PBS. The whole-cell extracts ( $40 \mu \mathrm{g}$ protein per lane) were subjected to SDS-8\%-PAGE. For 2D-PAGE, proteins were extracted from COS7, L6 and 3T3-L1 cells with $50 \mathrm{mM}$ Tris- $\mathrm{HCl}$ buffer, $\mathrm{pH} 8.0$, containing $8 \mathrm{M}$ urea, $1 \mathrm{mM}$ dithiothreitol and $1 \mathrm{mM}$ EDTA. The extracted proteins $(100 \mu \mathrm{g}$ protein/strip) were added with $5 \%$ 2-mercaptethanol and subjected to the first dimension of 2D-electrophoresis, which was performed using a $\mathrm{pH}$ 5-8 immobilized gradient strip (Bio-Rad Japan, Tokyo) on an apparatus for isoelectric focusing electrophoresis (Protean IEF Cell, Bio-Rad Japan). The strip was subjected to SDS-12\%-PAGE for the second dimension of twodimensional electrophoresis after equilibration for 10 min in $0.4 \mathrm{M}$ Tris- $\mathrm{HCl}$ buffer, $\mathrm{pH} 8.8$, containing $6 \mathrm{M}$ urea, $2 \%$ SDS, $20 \%$ glycerol and $2.5 \%$ iodoacetamide.

\section{Immunoprecipitation and Western blot analysis}

Extracts (70 $\mu \mathrm{g}$ protein) from 3T3-L1 adipocytes were incubated with protein G-sepharose preadsorbed with an anti-human UCP-2 antibody (Chemicon, Temecula, CA) overnight at $4^{\circ} \mathrm{C}$. The immunopellets were obtained by centrifugation at $5,000 \times G$ for $1 \mathrm{~min}$ at $4^{\circ} \mathrm{C}$. The whole-cell extracts or immunopellets were transferred to a polyvinylidene difluoride membrane after SDS-PAGE. The membrane was blocked with $4 \%$ skim milk and then incubated with an anti-V5 (Invitrogen) antibody, an anti-human UCP-2 antibody or anti-chicken $\beta$-actin antibody (Oncogene, San Diego, CA) for 1 hour at $37^{\circ} \mathrm{C}$. The amino acid sequence of transmembrane domain of human UCP-2 used for immunization has $100 \%$ homology to that of mouse or rat UCP-2, so that the antibody crossreacts with mouse or rat UCP-2. The bound antibodies were detected by using the enhanced chemiluminescence system (Amersham, Little Chalfont, UK). Signals were quantified by densitometric analysis, and each protein level was standardized by that of $\beta$-actin protein. Protein concentration was determined by Lowry' s method with bovine serum albumin as a standard (Lowry et al., 1951).

\section{Statistical analysis}

The experimental data were expressed as means \pm SD and statistically evaluated by analysis of variance (ANOVA) with SPSS computer programs (release 6.1; SPSS Japan, Tokyo). Individual differences between groups were assessed by using Duncan's multiple range test. Differences were considered significant at $\mathrm{P}<0.05$.

\section{Results}

Effects of unloading conditions on expression of secretedor membrane-type attractin in rat gastrocnemius muscle

Semi-quantitative RT-PCR analysis revealed that in rat gastrocnemius muscle, spaceflight and tail-suspension increased the amounts of secreted-type attractin mRNA at 4- and 2-folds, respectively. They did not increase the 

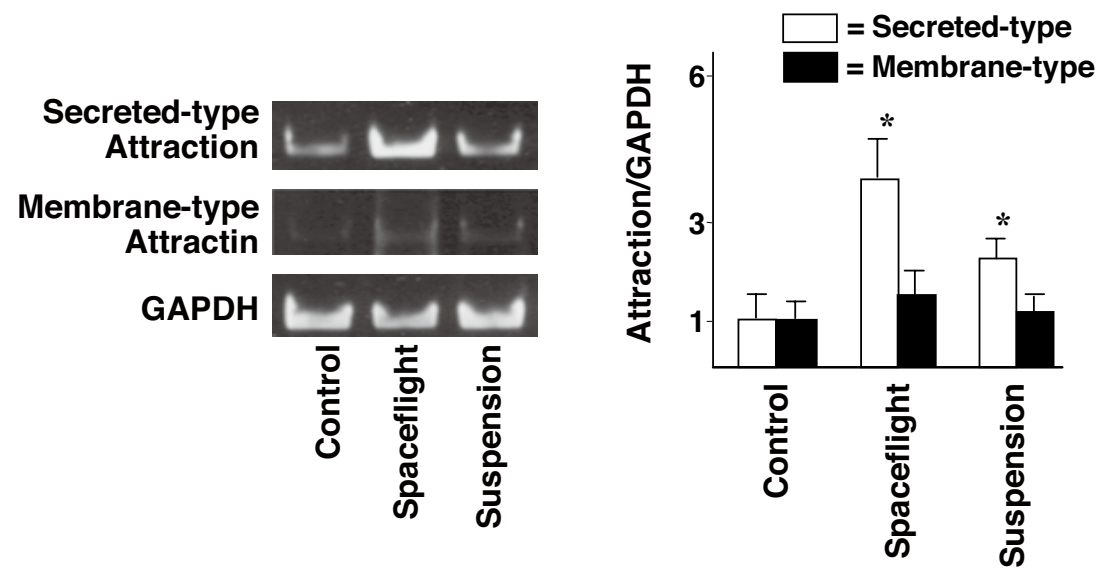

Fig. 2. RT-PCR analysis of secreted- or membrane-type attractin in rat gastrocnemius muscle.

Total RNA was isolated from rat gastrocnemius muscle exposed to unloading, spaceflight or tail-suspension. The values were normalized to the level of GAPDH mRNA. Data are mean $\pm S D(n=4)$. ${ }^{*} P<0.05$, compared with the value of ground control sample.

amount of membrane-type attractin mRNA, although skeletal muscle hardly expressed membrane-type attractin (Fig. 2).

Stimulatory effect of secreted-type attractin on UCP-2 expression in 3T3-L1 adipocytes

COS7 cells transfected with secreted-type attractin gene successfully expressed the protein for several days after transfection, though they hardly expressed attractin on Day 7 after transfection (Fig. 3A). Secreted-type attractin was accumulated in the culture media even on Day 7 after transfection. Twodimensional PAGE analysis revealed that transfection of secreted-type attractin or $\beta$-galactosidase hardly changed expression of other proteins in COS7 cells than attractin or $\beta$-galactosidase (data not shown).

We next examined effects of secreted-type attractin on expression of UCPs in L6 myotubes and 3T3-L1 adipocytes to elucidate its function of energy homeostasis. In 3T3-L1 adipocytes cocultured with the attractin-expressing COS7 cells, the amount of UCP-2 mRNA was higher than that in adipocytes co-cultured with COS7 cells expressing

Fig. 3. Effects of secreted-type attractin on 3T3-L1 adipocytes.

(A) Secreted-type attractin-overexpressing COS7 cells and the culture media were subjected to Western blot analysis by using an anti-V 5 antibody. (B) RNA was isolated from 3T3-L1 adipocytes at 48 hours after starting co-culturing with attractinor $\beta$-galactosidase-expressing COS7 cells. The UCP mRNA expression level was measured. Data are mean $\pm S D(n=4) .{ }^{*} P<0.05$, compared with the control samples. (C) Protein $(100 \mu \mathrm{g} /$ lane $)$ extracted from 3T3-L1 adipocytes was subjected to immunoprecipitation analysis, as described in Materials and Methods. Data are mean \pm SD $(n=4)$. ${ }^{*} \mathrm{P}<0.05$, compared with control samples.

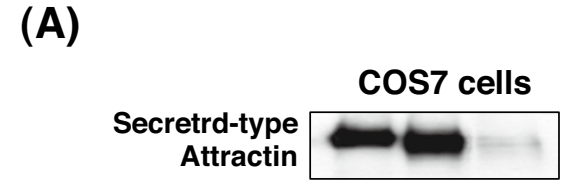

$\begin{array}{llll}\text { Time after transfection: } & 2 & 3 & 7\end{array}$

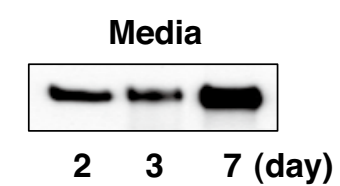

(B)

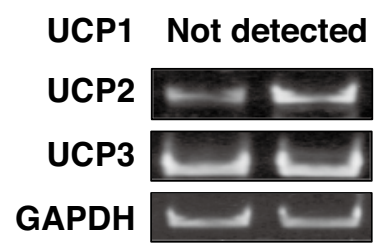

Transfection:ß-Gal Attractin
Transfection:B-Gal Attractin

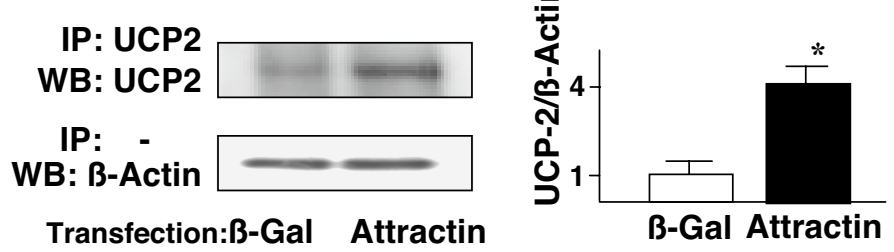

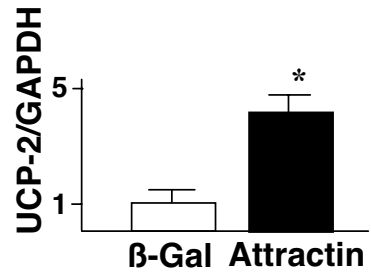

B-Gal Attractin

\section{(C)}


(A) 3T3-L1 cells

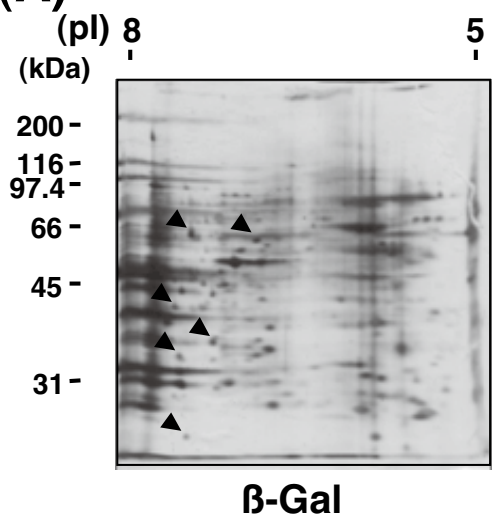

\section{(B) L6 cells}

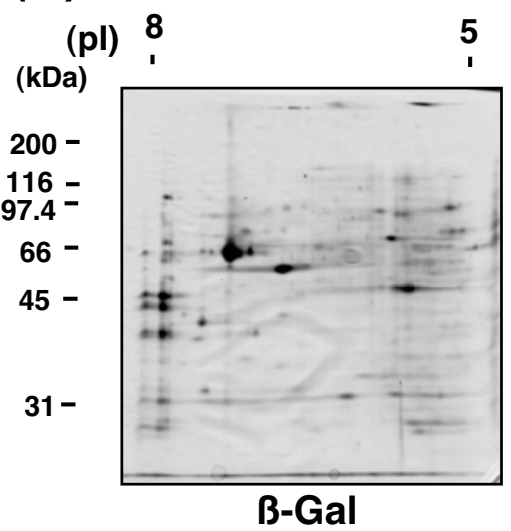

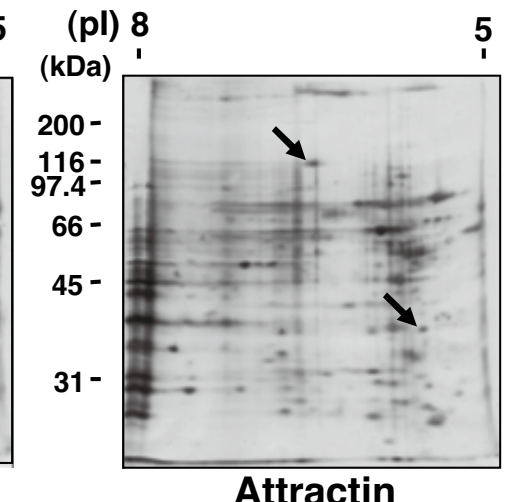

Attractin

5 ind examine whether these factors could induce expression of secreted-type attractin in skeletal muscle, we administered hydrogen peroxide or dexamethasone to rats. A long-term administration of hydrogen peroxide or dexamethasone did not change expression of secreted-type attractin mRNA in gastrocnemius muscle (Fig. 5).

\section{Discussion}

We previously examined expression of gastrocnemius muscle genes in spaceflown rats by DNA microarray analysis and found that expression of a secretory protein, called attractin, was remarkably upregulated by spaceflight (Nikawa et al., 2004). The present study showed that attractin is upregulated not only by spaceflight but also by tail-suspension. Nishizawa et al. (2004) have recently reported a unique skeletal muscle-derived secretory factor, musclin. They also showed that expression of musclin mRNA was regulated by nutritional changes and hormonal factors, especially insulin, and that recombinant musclin inhibited insulin-stimulated glucose uptake and glycogen synthesis in myocytes. Based on these observations, they suggest that skeletal muscles function not only as locomotorium but also as endocrine organ, regulating energy homeostasis. In this study, we also reasoned that attractin secreted from skeletal muscle hormonally regulated energy homeostasis in adipocytes during unloading.

Mitochondrial UCPs, particularly UCP-2 and UCP-3, have been reported to control energy metabolism (Gonzalez-Yanes and Sanchez-Margalet, 2003). UCP-2 and UCP-3 could export excess fatty acids out adipocytes.

(A, B) 3T3-L1 adipocytes or L6 myotubes were co-cultured with attractinexpressing COS7 cells for 48 hours, and proteins were extracted. The wholecell extracts ( $40 \mu \mathrm{g} / \mathrm{lane}$ ) were subjected to 2D-PAGE, as described in Materials and Methods. Proteins were visualized by silver staining. Arrows and arrow heads indicate proteins, the amounts of which were increased and decreased, respectively, by co-culturing.

transcript (Fig. 3C). In L6 cells co-cultured with the attractin-expressing COS7 cells, expressions of UCP-2 mRNA and protein were not changed (data not shown).

Effects of secreted-type attractin on comprehensive protein expression in 3T3-L1 adipocytes and L6 myotubes

We examined effects of secreted-type attractin on comprehensive protein expression in 3T3-L1 adipocytes and L6 myotubes. Expression of several proteins was upor down-regulated in 3T3-L1 adipocytes co-cultured with secreted-type attractin-transfected COS7 cells (Fig. 4A). However, secreted-type attractin hardly changed protein expression pattern in L6 myotubes (Fig. 4B).

Effects of hydrogen peroxide or dexamethasone on attractin expression in rat skeletal muscle.

Oxidative stress and serum glucocorticoid hormone have been reported to be accumulated or increased in organisms under unloading conditions (Kondo et al., 1991; Nikawa et al., 2004; Steffen and Musacchia of mitochondria in a situation of elevated mitochondiral fatty acid oxidation (Kozak and Harper, 2000; Goglia and Skulachev, 2003). Therefore, we focused on attractin-mediated UCP expression in adipocytes and skeletal muscle cells. We here found that attractin secreted into media upregulated expression of UCP-2 in 3T3-L1 adipocytes, but not in L6 myotubes. Based on these findings, it is likely that adipose tissue is a suitable target organ for attractin. In addition, the attractin did not change expression of UCP-3 even in adipocytes. There are controversial regulation systems for UCP-2 and UCP-3 expression. For example, starvation stimulates expression of UCP-3, but not UCP-2, in skeletal muscle (Gong et al., 1997). In adipose tissues, starvation upregulates expression of UCP-2, while it downregulates expression of UCP-3 (Memon et al., 2000; Gong et al., 1997). Since UCP-2 and UCP-3 have similar physiological roles, increased UCP-2 may compensate 


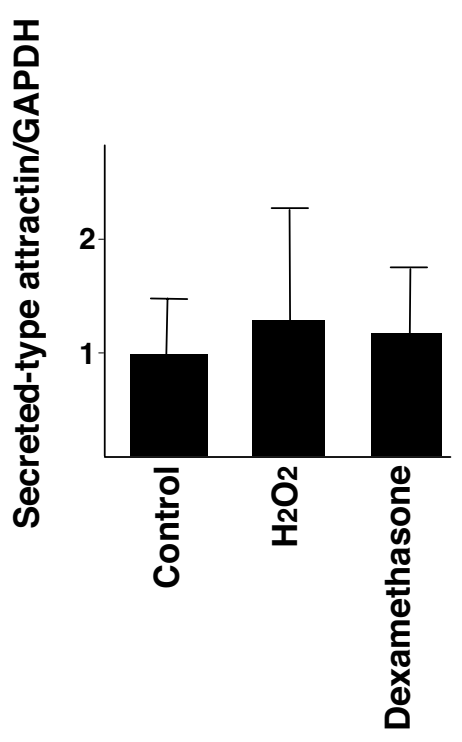

Fig. 5. Effects of hydrogen peroxide or dexamethasone on secreted-type attractin expression in rat gastrocnemius muscles. Total RNA was obtained from gastrocnemius muscles of rats treated with hydrogen peroxide or dexamethasone as described in Materials and Methods. Expression of secreted-type attractin transcripts was assessed by semi-quantitative RT-PCR. The values were normalized to the level of GAPDH mRNA. Data are mean $\pm S D(n=5)$.

for UCP-3 function in attractin-treated adipocytes. Further examinations are necessary to elucidate mechanism of attractin-mediated expression of UCP-2 in adipose tissues.

Besides attractin, various environmental and hormonal factors, such as fasting, leptin, TNF- $\alpha$ and thyroid hormone, upregulate expression of UCP-2 in white adipose tissues (Faggioni et al., 1998; Masaki et al., 1997; Memon et al., 2000). Since 2D-PAGE revealed that overexpression of secreted-type attractin did not change expression of other proteins, including TNF- $\alpha$, in COS7 cells (data not shown), attractin could directly affect expression of UCP-2 in adipocytes. During spaceflight or tail-suspension, secreted attractin may increase heat production or energy expenditure in adipocytes, instead of unloaded skeletal muscle.

To determine what factors mediate expression of secreted-type attractin in skeletal muscle, we examined effects of glucocorticoid and oxidative stress on attractin expression in skeletal muscle. We previously showed that expressions of various genes in rat duodenum, another stress-responsive tissue, were up- or down-regulated by glucocorticoid hormone or oxidative stress (Sato et al., 2006). For example, dexamethasone $(2 \mathrm{mg} / \mathrm{kg} / \mathrm{day}$, the same dosage in the present study) significantly upregulated the expression of mitochondrial HMG-CoA synthase, 2,4-dienoyl CoA reductase 1 and catechol- $O$ methyltransferase in rat duodenum. On the other hand, hydrogen peroxide $(100 \mathrm{mM})$ induced the upregulated expression of HMG-CoA reductase, cytosolic HMGCoA synthase, UDP-glucuronosyltransferase 1 A6 and catechol- $O$-methyltransferase. In our experiment, administration of neither dexamethasone nor hydrogen peroxide changed expression of secreted-type attractin. Treatment with insulin did not increase the amount of its transcripts in mouse $\mathrm{C} 2 \mathrm{C} 12$ myotubes, either (our unpublished data). It is unlikely that unloading-mediated stress, such as glucocorticoid hormone and oxidative stress, induces expression of attractin in skeletal muscle. Unfortunately, we did not find any hormonal factors stimulating expression of attractin. Identifying the mediator(s) is the next study subject to understand physiological importance of a novel myokine, attractin, for energy expenditure under unloading conditions.

\section{Acknowledgements}

This work was supported by a Grant-in-aid promoted by the Ministry of Education, Culture, Sports, Science and Technology to T. N.

\section{References}

Axelsson, J., Heimburger, O., Lindholm, B., Stenvinkel, P. (2005) Adipose tissue and its relation to inflammation: the role of adipokines. J. Ren. Nutr., 15,131-136.

Berger, M., Becker-Zimmermann, K., Herberg, L. (1982) Physical training in insulin-resistant states. Int. J. Obes., 1, S35-S40.

Biolo, G., Ciocchi, B., Stulle, M., Piccoli, A., Lorenzon, S., Dal Mas, V., Barazzoni, R., Zanetti, M., Guarnieri, G. (2005) Metabolic consequences of physical inactivity. J. Ren. Nutr., 15, 49-53.

Dridi, S., Onagbesan, O., Swennen, Q., Buyse, J., Decuypere, E., Taouis, M. (2004) Gene expression, tissue distribution and potential physiological role of uncoupling protein in avian species. Comp. Biochem. Physiol. A Mol. Integr. Physiol., 139, 273-283.

Faggioni, R., Shigenaga, J., Moser, A., Feingold, K.R., Grunfeld, C. (1998) Induction of UCP2 gene expression by LPS: a potential mechanism for increased thermogenesis during infection. Biochem. Biophys. Res. Commun., 244, 75-78.

Fedorak, R.N., Haeberlin, B., Empey, L.R., Cui, N., Nolen, H., III, Jewell, L.D., Friend, D.R. (1995) Colonic delivery of dexamethasone from a prodrug accelerates healing of colitis in rats without adrenal suppression. Gastroenterology, 108, 1688-1699.

Gianni, B., Beniamino, C., Manuela, S., Ariennna, P., Stefania, L., Viviana, D.M., Rocco, B., Michela, Z., Gianfranco, G. (2005) Metabolic consequences of physical inactivity. $J$. Ren. Nutr., 15, 49-53.

Goglia, F., Skulachev, V.P. (2003) A function for novel uncoupling proteins: antioxidant defense of mitochondrial matrix by translocating fatty acid peroxides from the inner to the outer membrane leaflet. FASEB J., 17, 1585-1591.

Gong, D.W., He, Y., Karas, M., Reitman, M. (1997) Uncoupling prote-n-3 is a mediator of thermogenesis regulated by 
thyroid hormone, beta 3-adrenergic agonists, and leptin. $J$. Biol. Chem., 272, 24129-24132.

Gonzalez-Yanes, C., Sanchez-Margalet, V. (2003) Pancreastatin, a chromogranin A-derived peptide, inhibits leptin and enhances UCP-2 expression in isolated rat adipocytes. Cell Mol. Life Sci., 60, 2749-2756.

He, L., Eldridge, A.G., Jackson, P.K., Gunn, T.M., Barsh, G.S. (2003) Accessory proteins for melanocortin signaling: attractin and mahogunin. Ann. N. Y. Acad. Sci., 994, 288-298.

He, L., Gunn, T.M., Bouley, D.M., Lu, X.Y., Watson, S.J., Schlossman, S.F., Duke-Cohan, J.S., Barsh, G.S. (2001) A biochemical function of attractin in agouti-induced pigmentation and obesity. Nat. Genet., 27, 40-47.

Hellgren, I., Drvota, V., Pieper, R., Enoksson, S., Blomberg, P., Islam, K.B., Sylven, C. (2000) Highly efficient cell-mediated gene transfer using non-viral vectors and FuGene6: in vitro and in vivo studies. Cell Mol. Life Sci., 57, 1326-1333.

Ikemoto, M., Nikawa, T., Takeda, S., Watanabe, C., Kitano, T., Baldwin, K.M., Izumi, R., Nonaka, I., Towatari, T., Teshima, S., Rokutan, K., Kishi, K. (2001) Space shuttle flight (STS-90) enhances degradation of rat myosin heavy chain in association with activation of ubiquitin-proteasome pathway. FASEB J., 15, 1279-1281.

Kondo, H., Miura, M., Itokawa, Y. (1991) Oxidative stress in skeletal muscle atrophied by immobilization. Acta Physiol. Scand., 142, 527-528.

Kozak, L.P., Harper, M.E. (2000) Mitochondrial uncoupling proteins in energy expenditure. Annu. Rev. Nutr., 20, 339-363.

Kuramoto, T., Kitada, K., Inui, T., Sasaki, Y., Ito, K., Hase, T., Kawagachi, S., Ogawa, Y., Nakao, K., Barsh, G.S., Nagao, M., Ushijima, T., Serikawa, T. (2001) Attractin/mahogany/ Zitter plays a critical role in myelination of the central nervous system. Proc. Natl. Acad. Sci. U.S.A., 98, 559-564.

Lindy, C.A. Jr., Wilson, J.D. (1965) Evidence for a contribution by the intestinal wall to the serum cholesterol of the rat. $J$. Lipid. Res., 58, 173-181.

Lowry, O.H., Rosebrough, N.J., Farr, A.L., Randall, R.J. (1951) Protein measurement with the folin phenol reagent. J. Biol. Chem., 193, 265-275.

Masaki, T., Yoshimatsu, H., Kakuma, T., Hidaka, S., Kurokawa, M., Sakata, T. (1997) Enhanced expression of uncoupling protein 2 gene in rat white adipose tissue and skeletal muscle following chronic treatment with thyroid hormone. FEBS Lett., 418, 323-326.

Memon, R.A., Hotamisligil, G.S., Wiesbrock, S.M., Uysal, K.T., Faggioni, R., Moser, A.H., Feingold, K.R., Grunfeld, C. (2000) Upregulation of uncoupling protein 2 mRNA in genetic obesity: lack of an essential role for leptin, hyperphagia, increased tissue lipid content, and TNF-alpha. Biochim. Biophys. Acta, 1484, 41-50.

Nikawa, T., Ishidoh, K., Hirasaka, K., Ishihara, I., Ikemoto, M., Kano, M., Kominami, E., Nonaka, I., Ogawa, T., Adams, G.R., Baldwin, K.M., Yasui, N., Kishi, K., Takeda, S. (2004) Skeletal muscle gene expression in space-flown rats. FASEB J., 18, 522-524.
Nishizawa, H., Matsuda, M., Yamada, Y., Kawai, K., Suzuki, E., Makishima, M., Kitamura, T., Shimomura, I. (2004) Musclin, a novel skeletal muscle-derived secretory factor. $J$. Biol. Chem., 279, 19391-19395.

Ogawa, T., Furochi, H., Mameoka, M., Hirasaka, K., Onishi, Y., Suzue, N., Oarada, M., Akamatsu, M., Akima, H., Fukunaga, T., Kishi, K., Yasui, N., Ishidoh, K., Fukuoka, H., Nikawa, T. (2006) Ubiquitin ligase gene expression in healthy volunteers with 20-day bedrest. Muscle Nerve, 34, 463-469.

Onishi, Y., Hirasaka, K., Ishihara, I., Oarada, M., Goto, J., Ogawa, T., Suzue, N., Nakano, S., Furochi, H., Ishidoh, K., Kishi, K., Nikawa, T. (2005) Identification of monoubiquitinated LDH-A in skeletal muscle cells exposed to oxidative stress. Biochem. Biophys. Res. Commun., 336, 799-806.

Ricquier, D. (2005) Respiration uncoupling and metabolism in the control of energy expenditure. Proc. Nutr. Soc., 64, $47-52$

Rousset, S., Alves-Guerra, M.C., Mozo, J., Miroux, B., Cassard-Doulcier, A.M., Bouillaud, F., Ricquier, D. (2004) The biology of mitochondrial uncoupling proteins. Diabetes, 53, 130-135.

Ryan, A.S. (2000) Insulin resistance with aging: effects of diet and exercise. Sports Med., 30, 327-346.

Sato, T, Yamamoto, H., Sawada N., Nashiki, K., Tsuji, M., Muto, K., Kume, K., Sasaki, H., Arai, H., Nikawa, T., Taketani, Y., Takeda, E. (2006) Restraint stress alters the duodenal expression of genes important for lipid metabolism in rat. Toxicology, 29, 248-261.

Smith, S.R., Gawronska-Kozak, B., Janderova, L., Nguyen, T., Murrell, A., Stephens, J.M., Mynatt, R.L. (2003) Agouti expression in human adipose tissue: functional consequences and increased expression in type 2 diabetes. Diabetes, 52, 2914-2922.

Steffen, J.M., Musacchia, X.J. (1987) Disuse atrophy, plasma corticosterones, and muscle glucocorticoid receptor levels. Aviat. Space Environ. Med., 58, 996-1000.

Stein, T.P., Wade, C.E. (2005) Metabolic consequences of muscle disuse atrophy. J. Nutr., 135, 1824-1828.

Tischler, M.E., Rosenberg, S., Satarug, S., Henriksen, E. J., Kirby, C.R., Tome, M., Chase, P. (1990) Different mechanisms of increased proteolysis in atrophy induced by denervation or unweighting of rat soleus muscle. Metabolism, 39, 756-763.

Wolkow, C.A., Iser, W.B. (2006) Uncoupling protein homologs may provide a link between mitochondria, metabolism and lifespan. Ageing Res. Rev., 5, 196-208. 